\title{
Pododermatite séptica em bovinos: evolução clínica da fase inicial
}

Luiz Antônio Franco da SILVA ${ }^{1}$

Rosana Rezende MORAES ${ }^{2}$

Alana Flávia ROMANI ${ }^{3}$

Maria Clorinda Soares

FIORAVANTI ${ }^{1}$

Paulo Henrique Jorge da CUNHA $^{1}$

José Renato Junqueira

BORGES 4

Sabrina Pereira MACEDO ${ }^{1}$

Adilson Donizeti

DAMASCENO ${ }^{1}$

Rogério Elias RABELO ${ }^{3}$

Andressa Mendes GARCIA $^{1}$

\section{Correspondência para:}

LUIZ ANTÔNIO FRANCO DA SILVA

Departamento de Medicina Veterinária

Universidade Federal de Goiás

Rdv.Goiânia-Nova Veneza, Km 0-Campus

II-Samambaia

Caixa Postal 131

74001-970-Goiania-GO

lafranco@vet.ufg.br

Recebido para publicação: 08/12/2005 Aprovado para publicação: 01/06/2006

\author{
1 - Departamento de Medicina Veterinária da Universidade Federal de \\ Goiás, Goiânia - GO \\ 2 - Ministério da Agricultura, Pecuária e Abastecimento, Goiânia - GO \\ 3 - Centro Avançado de Ciências Agrárias de Jataí da Universidade Federal \\ de Goiás, Jataí - GO \\ 4 - Faculdade de Agronomia e Medicina Veterinária da Universidade de \\ Brasília, Brasília - DF
}

\section{Resumo}

Esse estudo objetivou caracterizar clinicamente a fase inicial da pododermatite séptica em bovinos. Foram utilizadas 30 fêmeas bovinas, Girolando, de propriedades rurais do Estado de Goiás, submetidas às mesmas condições de manejo. Após o diagnóstico, foram submetidas a exame clínico específico dos dígitos, diariamente, por um período de quinze dias. Considerou-se o término da fase inicial a presença de fístula no espaço interdigital ou quando se completava o período de observação. Foram identificados o tipo de solo e o período do ano (chuvoso e seco). Durante a evolução da doença, o edema e a sensibilidade intensificaram de forma progressiva. Em 73,33\% dos casos, a enfermidade ocorreu no membro pélvico. Em 50,00\% observou-se edema moderado e 26,67\%, edema acentuado, considerando ambos os membros. A fistulação ocorreu em $83,33 \%$ animais doentes até o sexto dia, em $10 \%$ entre o sétimo e o décimo primeiro dia e em $6,67 \%$ não ocorreu. As áreas de fistulação ocorreram no ponto médio do espaço interdigital em 63,33\%; na região dorsal do espaço interdigital em 16,67\% e no cório-coronário da região abaxial do estojo córneo em $10,00 \%$ e na porção palmar/ plantar entre os talões em 3,33\% dos casos. A pododermatite séptica apresentou os mesmos sinais clínicos nas propriedades avaliadas e nos diferentes períodos do ano, variando apenas o tempo e o local de fistulação. O tempo médio transcorrido entre o diagnóstico e o a fistulação foi de cinco dias, sendo que o local de maior ocorrência foi o ponto médio do espaço interdigital.

\section{Introdução}

As doenças digitais em bovinos apresentam grande variação clínica e resultam em inúmeros prejuízos aos criatórios, atribuídos principalmente ao descarte prematuro, diminuição da produção de leite, perda de peso, redução da fertilidade e aos altos custos dos tratamentos ${ }^{1}$. A incidência é considerada alta em países que exploram bovinos especializados e, no Brasil, em determinadas regiões, avalia-se que enfermidades como as pododermatites atinjam números significativos². Vários fatores podem estar envolvidos na etiologia das doenças digitais em bovinos, podendo agir isoladamente ou em interdependência 3,4 , sendo que, para Moraes ${ }^{5}$, não se conhece bem o grau de envolvimento desses fatores na etiopatogenia dessas enfermidades.

A classificação das enfermidades dos dígitos dos bovinos pode ser realizada de maneiras distintas e a terminologia varia de país para país e entre os autores ${ }^{6}$. O diagnóstico fundamenta-se na anamnese, sinais clínicos e exames complementares. Um 
exame clínico rigoroso do membro e dos dígitos acometidos facilita a caracterização da lesão $0^{7,8}$. Contudo, clinicamente é muito difícil estabelecer a diferenciação entre algumas doenças digitais como a dermatite digital, flegmão interdigital e a pododermatite séptica, pois tais enfermidades na fase inicial apresentam sinais clínicos gerais muito semelhantes, caracterizados pela inflamação do tecido interdigital, seguida da ulceração da epiderme, podendo evoluir para o comprometimento do espaço interdigital, talões e outros tecidos adjacentes ${ }^{9,10}$.

Os animais portadores de pododermatite séptica em fase inicial, apresentam claudicação, edema, hiperemia da região ungular, perceptível sensibilidade ao toque e presença de pontos amarelados na pele do espaço interdigital, entretanto, não se observa lesões macroscópicas aparentes na pele 1,11,5,12 $^{\text {. }}$ Contudo, na evolução clínica da doença o edema agrava-se e o local torna-se mais sensível, evoluindo para fistulação no espaço interdigital, com presença de secreção sanguinolenta em alguns animais e massa caseosa com odor pútrido fluindo pela lesão em todos os bovinos enfermos. Quando não se faz qualquer tipo de tratamento, podem ocorrer lesões irreversíveis nos dígitos e, nas infecções crônicas, os cascos tornam-se longos e disformes ${ }^{7,13}$.

Apesar de vários autores ${ }^{1,11,5,7}$ fazerem referências aos sinais clínicos e estipularem o tempo de duração da fase inicial da pododermatite séptica, seus relatos não contemplam a avaliação sistemática da cronologia das modificações que ocorrem a partir da identificação da enfermidade até a fistulação do processo, interferindo substancialmente no estudo da etiopatogenia da enfermidade. Um outro aspecto não analisado nesses estudos está relacionado com os locais da fistulação, ficando as informações a esse respeito limitadas ao espaço interdigital. Acrescenta-se que a pododermatite séptica além de apresentar grande variação na evolução clínica entre países e de acordo com a região, sua etio- patogenia, em parte, é uma incógnita para pesquisadores de todo o mundo.

Esse estudo teve por objetivo avaliar os aspectos clínicos relacionados à evolução da fase inicial da pododermatite séptica em fêmeas bovinas em diferentes propriedades rurais de exploração leiteira.

\section{Materiais e Métodos}

O estudo foi realizado no período compreendido entre janeiro de 1999 e março de 2004 utilizando 30 fêmeas bovinas, da raça Girolando, procedentes de cinco propriedades rurais do Estado de Goiás, sendo três localizadas no município de Jataî (A, B e C), uma em Piracanjuba (D) e uma em Orizona (E). O tipo de solo predominante nas três primeiras era arenoso e, nas últimas, pedregoso. A semelhança entre o manejo, raça, histórico da manifestação clínica, ocorrência da enfermidade e a disponibilidade das propriedades em ceder os animais para o estudo foram os fatores considerados na escolha dos criatórios. Em todas as propriedades, os bovinos eram manejados extensivamente, no período chuvoso, em pastagens de Brachiaria sp. e na estação seca, mantidos semi-confinados, recebendo alimentação constituída de canade-açúcar e um suplemento mineral-protéico, cuja quantidade variava de acordo com a produção de leite de cada animal.

Para acompanhar a evolução clínica da enfermidade, a partir da confirmação do diagnóstico, os animais foram submetidos, diariamente, a exame clínico específico dos dígitos, conforme método descrito por Dirksen e Stober ${ }^{14}$ durante quinze dias. $\mathrm{Na}$ evolução da doença, considerou-se a presença de claudicação, edema e hiperemia da região ungular, a localização das fístulas e o aspecto do líquido que fluía no local fistulado, conforme descrito por Moraes ${ }^{5}$. Estabeleceu-se que o grau do edema observado antes da fistulação seria discreto, moderado e grave, quando o aumento do volume do membro fosse de 5\%,10\% e $20 \%$, respectivamente, em relação à medida 
da circunferência da extremidade distal, na região limítrofe entre a pele e o cório coronário do membro saudável contralateral. Quanto à localização das fístulas no espaço interdigital, foram estipulados quatro pontos possíveis de ocorrência do processo. Denominou-se região 1 quando a fístula ocorria na região dorsal do espaço interdigital, região 2 no ponto médio do espaço; região 3 quando a lesão era identificada na porção palmar/plantar entre os talões e região 4 caso a fistulação ocorresse no cório coronário da região abaxial do estojo córneo. Paralelamente ao diagnóstico, além de identificar o membro acometido, identificava-se a estação do ano em que o processo ocorreu.

Considerou-se como término da fase inicial a presença de fístula nas regiões consideradas neste estudo ou quando o período de observação completava 15 dias. Assim que a fístula era identificada, o animal era medicado com oxitetraciclina na dose de $20 \mathrm{mg} / \mathrm{kg}$ de peso corporal em intervalos de 48 horas até completar quatro aplicações, além do tratamento local da ferida em pedilúvio contendo solução de hipoclorito de sódio até a cicatrização da lesão ${ }^{15}$.

Os resultados obtidos foram analisados descritivamente, por meio de valores absolutos e percentuais, conforme Sampaio ${ }^{16}$.

\section{Resultados e Discussão}

Independente da propriedade de origem, em todos os bovinos os sinais clínicos da enfermidade, manifestados antes de ocorrer a fistulação, caracterizaram-se por claudicação, edema na região interdigital, hiperemia, hipertermia local, aumento da sensibilidade da porção distal do membro acometido e presença de pontos amarelados na pele interdigital, sem, contudo, identificar lesões macroscópicas de pele como fissuras e úlceras. Durante a evolução da doença, houve intensificação de forma progressiva do edema e da sensibilidade, culminando com o rompimento da pele e formação de fístula no espaço interdigital. Conforme relataram Silva ${ }^{12}$ e Borges $^{1}$, esses sinais clínicos são sugestivos de um processo inflamatório agudo e, segundo Blowey, Done e Cooley', são indicativos de pododermatite séptica.

Em 22 animais $(73,33 \%)$, a enfermidade foi diagnosticada nos membros pélvicos, sendo que em dez $(33,33 \%)$ o problema localizava-se no membro pélvico direito (MPD) e em doze (40\%) no membro pélvico esquerdo (MPE). Proporcionalmente, esses resultados estão de acordo com os encontrados por Nocek $^{7}$ e Ferreira ${ }^{17}$, os quais também apontaram ocorrência de doenças digitais superior a cinqüenta por cento para os membros pélvicos. Borges ${ }^{1}$ acrescentou que o contato com fezes e urina e o excesso de umidade, principalmente durante a ordenha, favorece o surgimento de doenças digitais nos membros pélvicos, sendo que a maior ocorrência de lesões no membro pélvico direito poderia estar relacionada à diminuição da circulação sanguínea no membro, uma vez que os bovinos geralmente repousam em decúbito esterno-abdominal direito, exercendo, conseqüentemente, maior pressão sobre esse. Em apenas oito $(26,67 \%$ ) bovinos, a doença foi diagnosticada nos membros torácicos, sendo em cinco $(16,67 \%)$ no membro torácico direito (MTD) e em três $(10 \%)$ no membro torácico esquerdo (MTE).

Do total de animais avaliados, sete $(23,33 \%)$ apresentaram edema discreto, em quinze $(50 \%)$ o processo foi considerado moderado e, em oito $(26,67 \%)$, classificouse como grave. Borges ${ }^{1}$, Demirkan, Murray e Carter ${ }^{6}$ e Berg e Franklin ${ }^{18}$ descreveram os sinais clínicos iniciais da pododermatite infecciosa, destacando a claudicação repentina e severa acometendo geralmente um único membro, queda de produção, inflamação da pele interdigital e tecidos adjacentes, separação das úngulas pelo edema simétrico da região digital, amarelamento da pele interdigital e, com a evolução clínica, o surgimento de fissuras na mesma. Apesar de considerar o edema um achado clínico 
importante, os autores não se preocuparam em estabelecer os graus variados do processo, conforme observado nesse estudo.

Avaliando o tempo de fistulação na região digital dos membros comprometidos, verificou-se que a lesão ocorreu em três $(10 \%)$ animais até o terceiro dia após o diagnóstico da enfermidade, em seis $(20 \%)$, a presença de fístula foi observada no quarto dia e, em onze $(36,67 \%)$ fêmeas, a fístula foi detectada no quinto dia. A partir desse momento, no sexto dia, a fistulação foi identificada em cinco $(10 \%)$ animais, no oitavo dia, em dois $(6,66 \%)$ e, no $11^{\circ}$ dia, a presença de fístula foi diagnosticada em apenas uma (3,33\%) fêmea. Em duas (6,67\%) fêmeas, ao concluir o período de observação de quinze dias, não havia ocorrido a fistulação. Moraes ${ }^{5}$ encontrou uma duração média de 5,6 dias na primeira fase da enfermidade, considerando o dia em que iniciou a claudicação até o dia em que ocorreu a fistulação e Jordão ${ }^{19}$ sugeriu um curso de sete a dez dias para essa fase da doença. Nocek ${ }^{7}$ e Greenough ${ }^{20,11}$ propuseram três estágios de evolução da enfermidade, sendo o agudo nos primeiros dez dias, o subagudo, de dez a 45 dias e o crônico acima de 45 dias.

Observando o tempo decorrido entre o início da avaliação e a fistulação, verificou-se que nas propriedades $\mathrm{A}, \mathrm{B}$ e C, de um total de 19 bovinos enfermos, em apenas dois $(10,53 \%)$ animais a fístula foi identificada a partir do quinto dia de observação, sendo que em dois $(10,53 \%)$, o processo não fistulou. Nas demais propriedades ( $\mathrm{D}$ e E), de 11 bovinos portadores da doença, em todos ocorreu fistulação, sendo que em quatro $(36,36 \%)$ a lesão foi detectada a partir do quinto dia e, em um $(9,09 \%)$, a fístula foi observada somente no $11^{\circ}$ dia de avaliação. Esses resultados indicam que o tempo de evolução da fase inicial da enfermidade pode variar de acordo com o ambiente em que os animais permanecem (Quadro 1). Borges ${ }^{1}$ considerou o período compreendido a partir da identificação dos primeiros sinais da enfermidade até o $11^{\circ}$ dia como portadores da fase inicial da pododermatite bovina, mas ao contrário desse estudo, não fez o acompanhamento sistemático da evolução do processo mórbido e não correlacionou essa fase com a presença de fístula no espaço interdigital.

Não se observou variação na apresentação clínica da enfermidade, tanto nos casos diagnosticados na estação seca do ano como na estação chuvosa, entretanto, a ocorrência manifestou-se de forma diferente. Dentre os 19 casos da enfermidade diagnosticados nas propriedades A, B e C, em $14(73,68 \%)$ a doença foi identificada no período seco e, em apenas cinco $(26,32 \%)$, ocorreu no período chuvoso. É provável que a maior concentração de animais e o excesso de sujidades verificados nas instalações, por ocasião da suplementação dos animais no período seco do ano, possam ter contribuído para o aumento do número de animais enfermos nessa época nas propriedades localizadas no município de Jataí. Curiosamente, nas propriedades D e E, cujo solo era pedregoso, a maior ocorrência da enfermidade foi evidenciada na estação chuvosa, com sete $(63,64 \%)$ bovinos doentes de um total de 11 diagnosticados. A maior precipitação pluviométrica observada na região no período das chuvas provavelmente interferiu na resistência do estojo córneo que, somado ao solo pedregoso da região, pode ter provocado microlesões nos dígitos e conseqüentemente favorecido a penetração dos microrganismos desencadeantes da enfermidade. Yagger, Scott e Wilcock ${ }^{21}$ afirmaram que qualquer lesão que comprometa a integridade da pele favorece potenciais patógenos. Segundo Ebeid ${ }^{22}$ e Singh, Ward e Murray ${ }^{23}$, terrenos pedregosos, traumatismos e laminite podem facilitar a penetração nos dígitos de agentes bacterianos, como Dichelobacter nodosus e Fusobacterium necrophorum, desencadeando a pododermatite. Smith ${ }^{24}$ afirmou que a pododermatite é observada durante todo o ano e a prevalência é maior nas estações 
úmidas. Já Fraser ${ }^{25}$ relatou que esta enfermidade pode ocorrer com freqüência nas estações secas, quando o terreno está firme. Segundo Greenough ${ }^{26}$, a doença é mais comum durante o inverno, período em que os animais, por estarem estabulados,

Tabela 1 - Distribuição de fêmeas bovinas portadoras de pododermatite séptica na fase inicial, de acordo com o município, a propriedade de origem, o tempo decorrido entre o diagnóstico e a fistulação no espaço interdigital e a gravidade do edema, em cinco criatórios de bovinos da raça Girolando, no Estado de Goiás, no período compreendido entre janeiro de 1999 e março de 2004.

\begin{tabular}{|c|c|c|c|c|c|c|c|c|c|c|c|c|c|c|}
\hline \multirow{2}{*}{$\begin{array}{l}\text { Mu } \\
\text { nicí } \\
\text { pio }\end{array}$} & \multirow{2}{*}{$\begin{array}{l}\text { Propri } \\
\text { edade }\end{array}$} & \multicolumn{2}{|c|}{$\begin{array}{c}\text { Período do } \\
\text { ano* }^{*}\end{array}$} & \multicolumn{7}{|c|}{ Tempo de fistulação (Dias)** } & \multicolumn{3}{|c|}{$\begin{array}{c}\text { Grau do } \\
\text { edema*** }\end{array}$} & \multirow{2}{*}{$\begin{array}{l}\mathrm{TO} \\
\mathrm{TAL}\end{array}$} \\
\hline & & $\begin{array}{c}\mathrm{CH} \\
\mathrm{U}\end{array}$ & SEC & $\begin{array}{c}\text { TR } \\
E\end{array}$ & $\begin{array}{l}\mathrm{QU} \\
\mathrm{A}\end{array}$ & $\begin{array}{l}\mathrm{Cl} \\
\mathrm{N}\end{array}$ & SEl & $\begin{array}{l}\text { Ol } \\
\text { T }\end{array}$ & $\begin{array}{c}\mathrm{O} \\
\mathrm{NZ}\end{array}$ & NF & $\mathrm{D}$ & $M$ & $G$ & \\
\hline \multirow[t]{3}{*}{ Jataí } & A & 3 & 3 & 2 & 3 & 1 & - & - & - & - & 2 & 3 & 1 & 6 \\
\hline & B & 1 & 6 & 1 & 1 & 3 & 1 & - & - & 1 & 2 & 3 & 2 & 7 \\
\hline & C & 1 & 5 & - & 1 & 3 & - & 1 & - & 1 & 1 & 3 & 2 & 6 \\
\hline $\begin{array}{l}\text { Pira } \\
\text { can } \\
\text { jub } \\
\text { a }\end{array}$ & $\mathrm{D}$ & 4 & 1 & 1 & 1 & 2 & 1 & - & - & - & 1 & 2 & 2 & 5 \\
\hline $\begin{array}{l}\text { Ori } \\
\text { zo } \\
\text { na }\end{array}$ & $E$ & 3 & 3 & 1 & - & 2 & 1 & 1 & 1 & - & 1 & 3 & 2 & 6 \\
\hline & TAL & 12 & 18 & 5 & 6 & 11 & 3 & 2 & 1 & 2 & 7 & 15 & 8 & 30 \\
\hline
\end{tabular}

*CHU: Chuvoso; SEC: Seco; **TRE: Três; QUA: Quatro; CIN: Cinco; SEl: Seis; OIT: Oito; ONZ: Onze; ** NF: Não Fistulou; ***D: Discreto; M: Moderado; G: Grave.

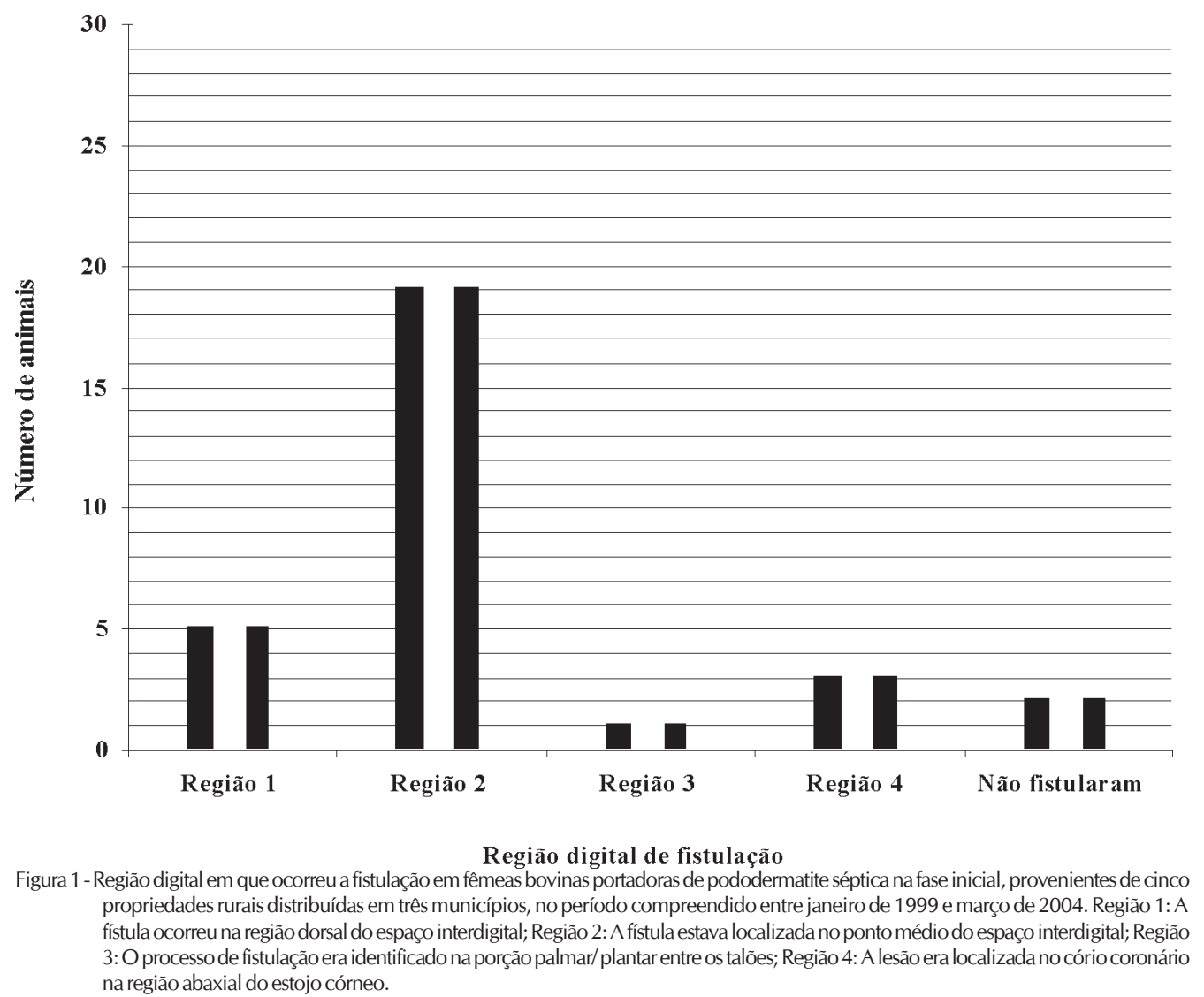


passam horas sobre suas excretas, o que está em conformidade com o observado nas propriedades A, B e C, mas difere dos achados observados nas propriedades $\mathrm{D}$ e $\mathrm{E}$, apesar de em todas as propriedades os animais serem manejados em sistema de semiconfinamento no período seco do ano.

Com relação ao local de fistulação, dos trinta casos diagnosticados, a lesão foi identificada na região 1 em cinco (16,67\%) animais, na região 2 em 19 (63,33\%), na região 3 em um $(3,33 \%)$ e, na região 4 em três $(10,00 \%)$ bovinos. Em dois (6,67\%) animais, não ocorreu a fistulação (Figura 1). Na literatura consultada, os autores Borges ${ }^{1}$, Greenough $^{11}$ e Moraes $^{5}$ mencionaram a ocorrência de fístulas no desenvolvimento da pododerma-tite séptica, mas, ao contrário desse estudo, não registraram o local em que a lesão ocorre com maior freqüência.

\section{Conclusões}

A pododermatite séptica apresentou os mesmos sinais clínicos nas propriedades avaliadas e nas diferentes estações do ano, variando apenas o tempo e o local de fistulação. O tempo médio transcorrido entre o diagnóstico da enfermidade e o desenvolvimento de fístula foi de cinco dias, sendo que o local de maior ocorrência foi o ponto médio do espaço interdigital.

\section{Bovine septic podermatitis: clinial evolution of the early stage}

\section{Abstract}

This study aimed to describe the clinical signs of the initial phase of septic pododermatitis in thirty female girolando bovines under the same handling care from different farms in State of Goiás. Following the diagnosis, they were submitted to daily clinical examination of the hoofs during fifteen days. It was considered as the end of the initial phase the presence of fistula in interdigital space or when the observation time over. It was observed the farm's soil type and the period of the year (if rainy and dryness). During the disease evolution, edema and pain increased in progressive order until skin disruption and fistula formation. In $73,33 \%$, the illness envolved the hind limbs. In $50,00 \%$ it was observed moderate edema and $26,67 \%$ intense edema in both limbs. Fistula occurred in 83,33\% ill animals until sixth day, in 10\% between seventh and eleventh days and in $6,67 \%$ of the cases it was't observed. Fistulation areas were middle point of interdigital space in $63,33 \%$; dorsal region of interdigital space in $16,67 \%$ and in coronary corium of the abaxial region of the hoof in $10,00 \%$ and in palmar/plantar region between coronary cushion in $3,33 \%$ of cases. The septic pododermatitis showed the same clinical signs in farms considered in this study and in different periods of the year, differing in time and fistula site. The average time from diagnosis and fistulation was five days. The more commom site was the middle point of the interdigital space.

\section{Referências}

1 BORGES, N. C. Caracterização do fluido rumenal e dos parâmetros clínicos - laboratoriais de bovinos com pododermatite. $69 \mathrm{f}$. Dissertação (Mestrado em Medicina Veterinária) - Escola de Veterinária, Universidade Federal de Goiás, Goiânia, 1998

2 BORGES, J. R. J.; PITOMBO, C. A.; SANTIAGO, S.
Key-words:

Bovine.

Digital diseases. Clinical evolution. Septic dermatitis. 
4 CORBELLINI, C. N. Factores nutricionales de riesgo para las afecciones podales. In: JORNADA-TALLER PARA MÉDICOS VETERINÁRIOS, 1., 1994, Navarro. Anais..., 1994, p. 1 - 5.

5 MORAES, R. R. Caracterização clínica, laboratorial e anatomopatológica da fase inicial da inflamação do tecido interdigital de bovinos da raça Girolanda. 2000. 110 f. Dissertação (Mestrado em Medicina Veterinária). Escola de Veterinária, Universidade Federal de Goiás, Goiânia, 2000.

6 DEMIRKAN, I.; MURRAY, R. D.; CARTER, S. D. Skin diseases of the bovine digit associated with lameness. Veterinary Bulletin, v. 70, n. 2, p. 149-171, 2000.

7 NOCEK, J. E. Hoof care for dairy cattle. Fort Atkison: W. D. Hoard \& Sons Company, 1993. 34 p.

8 RAVEN, E. T. Cattle footcare and clam trimming. Baltimore: Farming Press Book, 1997. 50 p.

9 BLOWEY, R. W.; DONE, S. H.; COOLEY, W. Observations on the pathogenesis of digital dermatitis in cattle. The Veterinary Record, v. 135, p. 115-117, 1994.

10 NICOLETTI, J. L. M. Manual de podologia bovina. Barueri: Manole, 2004. 125 p.

11 GREENOUGH, P. R. Diseases of the feet of dairy cows - Infectious disease of the interdigital space. In: CONGRESSO BRASILEIRO DE CIRURGIA E ANESTESIOLOGIA VETERINÁRIA, 4., 2000, Goiânia. Anais eletrônicos [CD-ROM], Goiânia: Temma, 2000.

12 SILVA, C. A. Identificação e isolamento do Dichelobacter nodosus e do Fusobacterium necrophorum de bovinos portadores de pododermatite, relações com a etiopatogenia, dados edafoclimáticos e avaliação do tratamento. 1997, 81 f. Dissertação (Mestrado em Medicina Vererinária). Escola de Veterinária, Universidade Federal de Goiás, Goiânia, 1997.

13 CARLTON, W. W.; McGaVIN, M. D. Patologia veterinária especial. 2 ed. Porto Alegre: Artmed, 1998. $672 \mathrm{p}$.

14 DIRKSEN, G.; STOBER, E. M. As afecções dos cascos dos bovinos: melhor prevenir do que curar. A Hora Veterinária, v. 1, n. 3, p. 13-19, 1981.

15 SILVA, L. A. F.; COELHO, K. O.; MESQUITA, A. J.; COUTO, D. V.; FIORAVANTI, M. C. S., SOUZA, T. M.; ATAYDE, I. B. The effects of sodium hypochloride on mesophilic aerobic bacteria of interdigital space of healthy cattle. Israel Journal of Veterinary Medicine, $v$. 57, n. 3, p. 101-104, 2002.

16 SAMPAIO, I. B. M. Estatística aplicada à experimentação animal. Belo Horizonte: Fundação de Ensino e Pesquisa em Medicina Veterinária e Zootecnia, 1998. 221 p.

17 FERREIRA, P. M. Enfermidades podais em rebanho leiteiro confinado. 2003. 79 f. Tese (Doutorado em Medicina Veterinária) - Escola Veterinária, Universidade Federal de Minas Gerais, Belo Horizonte, 2003

18 BERG, J. N.; FRANKLIN, C. L. Interdigital phlegmon and interdigital necrobacilosis. Acute foot rot of cattle: Considerations in etiology, diagnosis and treatment. In: INTERNATIONAL SYMPOSIUM ON DISORDERS OF THE RUMINANT DIGIT, 11., INTERNATIONAL CONFERENCE ON BOVINE LAMENESS, 3., 2000, Parma. Anais eletrônicos [CD-ROM], 2000.

19 JORDÃO, L. P. Por que mancam as vacas? Revista dos Criadores, n. 149, p. 23-25, 1988.

20 GREENOUGH, P. R. Observations on some of the diseases of the bovine foot, part II. The Veterinary Record, v. 74, n. 2, p. 53-63, 1962.

21 YAGGER, J. A.; SCOTT, D. W.; WILCOCK, B. P. The skin and appendiges. In: JUBB, K. V. F.; KENNEDY, P. C.; PALMER, N. Pathology of domestic animals. 5 ed. San Diego: Academic Press, 1993, p. 664 - 670.

22 EBEID, M. Bovine laminitis: a review. Veterinary Bulletin, v. 63, n. 3, p. 205-213, 1993.

23 SINGH, S. S.; WARD, W. R.; MURRAY, R. D. Aetiology and pathogenesis of sole lesions causing lameness in cattle: a review. Veterinary Bulletin, v. 63, n. 4, p. 303-14, 1993.

$24 \mathrm{SMITH}, \mathrm{B}$. P. Tratado de medicina interna de grandes animais. São Paulo: Manole, 1994. 1738 p.

25 FRASER, C. M. Manual Merck de veterinária. 6. ed., São Paulo: Roca, 1991. 1803 p.

26 GREENOUGH, P. R. Cascos irregulares são sinais de problemas. Balde Branco, n. 388, p. 9 -13, 1997. 